\title{
Vitamin D alleviates skeletal muscle loss and insulin resistance by inducing vitamin D receptor expression and regulating the AMPK/SIRT1 signaling pathway in mice
}

\author{
Aijuan $\mathrm{LI}^{1}$, Pengcheng SHEN², Sijia LIU ${ }^{1}$, Jiao WANG ${ }^{1}$, Jingru ZENG ${ }^{1}$, Chunping DU ${ }^{1 \star}$ (D)
}

\begin{abstract}
Vitamin D (VD) was reported to play protective roles in skeletal muscle. This study aimed to explore whether endoplasmic reticulum (ER) stress inhibition is associated with the protective effects of VD/VD receptor (VDR) signaling on skeletal muscle functions. C2C12 skeletal muscle cells were treated with palmitic acid (PA) and then incubated with different concentrations of 1,25-(OH)2-vitamin D3 (VD3), and we found that VD3 improved the impaired cell viability induced by PA and increased VDR expression in a dose-dependent manner. Then $100 \mathrm{nM}$ VD3 treatment and VDR overexpression both ameliorated PA-induced ER stress, apoptosis, inflammation and glucose uptake inhibition in C2C12 myocytes. Furthermore, VDR knockdown reversed the protective effects of VD3 on C2C12 cell functions. Additionally, PA-treated C2C12 cells were treated with VD3 alone or together with AMPK signaling inhibitor Compound C. VD3 promoted phosphorylation of AMPK and SIRT1 expression, while Compound $\mathrm{C}$ reversed these effects and abolished the protective effects of VD3 in C2C12 cells. High-fat diet (HFD)-fed mice were treated with VD3, and VD3 alleviated skeletal muscle loss and insulin resistance in mice. In conclusion, VD inhibited AMPK/SIRT1-mediated ER stress by increasing VDR expression, and further ameliorated skeletal muscle loss and insulin resistance in mice.
\end{abstract}

Keywords: VD; VDR; skeletal muscle loss; insulin resistance; AMPK/SIRT1 signaling pathway; endoplasmic reticulum stress.

Practical Application: This study suggested that Vitamin D3 (VD3) increased VD receptor (VDR) expression in a dose-dependent manner in C2C12 skeletal muscle cells. VD3 treatment ameliorated palmitic acid (PA)-induced ER stress, apoptosis, inflammation, and glucose uptake inhibition by promoting VDR expression in C2C12 myocytes. Moreover, AMPK/SIRT1 activation is involved in the protective effects of VD3 on C2C12 myocytes. More importantly, we found that VD3 treatment alleviated skeletal muscle loss and insulin resistance in high-fat diet (HFD)-fed mice.

\section{Introduction}

Skeletal muscle is the most abundant tissue in the human body, accounting for about $40 \%$ of total body weight and $50-70 \%$ of total protein content. Skeletal muscle mass and strength play a crucial role in human health, which contributes to body balance, soft tissue support, skeletal movement and glucose homeostasis. Skeletal muscle mass is strictly dependent on the appropriate balance between protein degradation and synthesis, and its loss is associated with weakness, fatigue, and insulin resistance (Frontera \& Ochala, 2015). Skeletal muscle is the major site for insulin-stimulated glucose uptake (Kelley et al., 2002), and skeletal muscle loss is widely viewed as being critical for the development of whole-body insulin resistance and type 2 diabetes. In fact, it is revealed that controlling skeletal muscle loss can reduce morbidity and mortality associated with diseases such as cancer cachexia, sarcopenia and diabetic myopathy.

Endoplasmic reticulum (ER) stress intersects with various inflammatory and stress signaling pathways, which has emerged as a key player in the progression of multiple diseases. ER is a cellular organelle for protein synthesis, folding, and trafficking, and also serve as a major signal transduction organelle. ER stress

is a stress mechanism initiated by dysregulation of calcium homeostasis and accumulation of unfolded or misfolded proteins. ER stress induces the activation of the unfolded protein response (UPR) to restore ER functions (Ron, 2002). Emerging evidence has indicated ER stress as a potential mechanism responsible for apoptosis, inflammation and insulin resistance in skeletal muscle. For instance, increased ER stress and ubiquitin-proteasome system activity promoted myocyte apoptosis in the skeletal muscle of diabetic rats (Reddy et al., 2018). Enhanced ER stress is observed in skeletal muscle of pregnant women with gestational diabetes mellitus, which can regulate inflammation and insulin resistance in pregnant women (Liong \& Lappas, 2016). Loss of T-type calcium channel function leads to terminal mitochondrial-related apoptosis in $\mathrm{C} 2 \mathrm{C} 12$ myotubes and skeletal muscle by activating ER stress signaling (Chen et al., 2020). Current evidence has proposed that chemical inhibition of ER stress ameliorates inflammation insulin resistance in skeletal muscle. For example, Fenofibrate-mediated inhibition of ER stress significantly improved high-fat diet-induced and palmitate-induced inflammation and insulin resistance in skeletal muscle (Dai et al., 2016). Fatty acid binding protein 4 (FABP4) 
inhibitor BMS309403 reduced saturated-fatty-acid-induced ER stress-associated inflammation in skeletal muscle by suppressing p38 MAPK activation (Bosquet et al., 2018). Therefore, screening for substances that ameliorate ER stress is important to prevent skeletal muscle injury and insulin resistance.

Vitamin D (VD) is a fat-soluble vitamin mainly derived from animal foods, which can be converted into a biologically active form, 1,25-(OH) ${ }_{2}$-vitamin D3 (VD3), in human body after ingestion. Recently, the protective effect of VD on skeletal muscle has attracted increasing attention. Previous studies demonstrated that low vitamin D status was closely associated with reduced muscle mass, strength, and function (HassanSmith et al., 2017; Visser et al., 2003). VD participated in the regulation of primary human skeletal muscle cell proliferation, differentiation, protein synthesis and bioenergetics by altering the expression of myogenic regulatory factors (Montenegro et al., 2019). It has been proved that treatment with VD3 results in a persistent increase of vitamin $\mathrm{D}$ receptor (VDR) in human skeletal muscle (Pojednic et al., 2015). More importantly, VD3 exerted its actions through VDR, and downregulation of VDR is relevant to skeletal muscle atrophy and functional decline (Bass et al., 2021). VD has been reported to play protective roles in multiple diseases by suppressing ER stress (Guo et al., 2017; Hu et al., 2021). However, the exact underlying mechanisms of VD-related pathways in skeletal muscle functions are unclear, and whether ER stress is associated with the protective effects of VD/VDR signaling on skeletal muscle functions has not been elucidated.

Hence, the main purpose of the present study is to explored the association between VD/VDR signaling and ER stress in skeletal muscle from in vivo and in vitro experiments.

\section{Methods}

\subsection{Cell culture and treatment}

Mouse $\mathrm{C} 2 \mathrm{C} 12$ myoblast cell line was purchased from ATCC (American Type Culture Collection; Manassas, VA, USA). Cells were cultured in Dulbecco's Modified Eagle Medium (DMEM; Gibco, Grand Island, NY, USA) supplemented with $10 \%$ fetal bovine serum (FBS; Gibco, Grand Island, USA), $100 \mathrm{U} / \mathrm{mL}$ of penicillin, and $100 \mu \mathrm{g} / \mathrm{mL}$ of streptomycin (Gibco, Grand Island, USA) in a humidified atmosphere with $5 \% \mathrm{CO}_{2}$ at $37^{\circ} \mathrm{C}$. At $90 \%$ confluence, cells were induced to differentiated into myotubes with $2 \%$ horse serum (Gibco, Grand Island, USA) for 4 days. After differentiation, C2C12 myotubes were incubated with BSA-conjugated palmitic acid (PA, $0.5 \mathrm{mM}$; Sigma-Aldrich, St. Louis, MO, USA) for $24 \mathrm{~h}$. For PA solution preparation, BSA-conjugated PA was prepared following a modified method (Chavez et al., 2003). Briefly, PA was completely dissolved in absolute ethanol and then diluted in DMEM containing $2 \%$ fatty acid-free BSA. The solution was filtered, aliquoted, and stored at $-20^{\circ} \mathrm{C}$ before use. And the same amount of ethanol instead of PA was used as control group. Then VD3 (Sigma-Aldrich, St. Louis, MO, USA) was dissolved in absolute ethanol to prepare different concentrations of VD3 solution. And the PA-treated $\mathrm{C} 2 \mathrm{C} 12$ cells were incubated with different concentrations of VD3 solution for an additional $24 \mathrm{~h}$.

\subsection{Cell transfection}

The VDR overexpression plasmid (pcDNA-VDR), small interfering RNA against VDR (si-HSPA8), and their corresponding negative controls (vector, scramble) were obtained from (Gene chem Co. Ltd., Shanghai, China). Cell transfection were performed with the Lipofectamine 3000 Transfection Reagent (Invitrogen, Carlsbad, CA) according to the manufacturer's instructions. After transfection for $48 \mathrm{~h}$, cells were harvested for subsequent experiments.

\subsection{Western blotting}

$\mathrm{C} 2 \mathrm{C} 12$ cells or skeletal muscle tissues were lysed in RIPA lysis buffer (Beyotime, Shanghai, China). The total protein concentration was measured by using BCA Protein Kit (Beyotime, Shanghai, China). Next, proteins were separated on SDS-PAGE under the following conditions: $70 \mathrm{~V}$ for $30 \mathrm{~min}$, followed by $120 \mathrm{~V}$ for $90 \mathrm{~min}$. And then the protein bands were transferred onto polyvinylidene fluoride (PVDF) membranes (Millipore, Bedford, MA, USA) at $300 \mathrm{~mA}$ for $2 \mathrm{~h}$. The membranes were blocked with $5 \%$ non-fat milk for $2 \mathrm{~h}$ at room temperature and then incubated overnight at $4{ }^{\circ} \mathrm{C}$ with the following primary antibodies: anti-VDR antibody (1:1000, ab89626, Abcam), anti-GRP78 antibody (1:1000, ab21685, Abcam), anti-CHOP antibody (1:1000, ab11419, Abcam), anti-ATF6 antibody (1:1000, ab203119, Abcam), anti-MMP-9 antibody (1:1000, ab76003, Abcam), anti-p-AMPK antibody (1:1000, ab23875, Abcam), anti-AMPK antibody (1:1000, ab80039, Abcam), antiSIRT1 antibody (1:1000, ab189494, Abcam) and anti-GAPDH antibody (1:2500, ab9485, Abcam), Then the membranes were incubated with horseradish peroxidase (HRP)-conjugated goat anti-rabbit $\operatorname{IgG}(1: 2000, \mathrm{Abcam}$, ab6721) or HRP-conjugated goat anti-mouse IgG (1:2000, Abcam, ab6789) for $1 \mathrm{~h}$. GAPDH was used as endogenous control. The protein bands were visualized with ECL detection reagents (Pierce, Rockford, IL, USA) and analyzed with ImageJ software (National Institutes of Health, Bethesda, Md, USA).

\subsection{CCK-8 assay}

C2C12 cell viability was detected with Cell Counting Kit-8 (CCK-8) assay (Sigma-Aldrich, St. Louis, MO, USA). Briefly, C2C12 cells were seeded into 96-well plates. After incubation for $0,24,48$ and $72 \mathrm{~h}, 10 \mu \mathrm{L}$ of CCK-8 solution was added to each well and incubated with C2C12 cells for another $2 \mathrm{~h}$ in a humidified atmosphere with $5 \% \mathrm{CO}_{2}$ at $37^{\circ} \mathrm{C}$. The absorbance of each well at $450 \mathrm{~nm}$ was measured with a microplate reader (Molecular Devices, Shanghai, China).

\subsection{Cell apoptosis analysis}

C2C12 cell apoptosis was detected with a Annexin V-FITC/ PI apoptosis detection kit (BD Bioscience, San Jose, CA, USA). Briefly, C2C12 cells $\left(1 \times 10^{6}\right.$ cells $\left./ \mathrm{mL}\right)$ were resuspended in $200 \mu \mathrm{L}$ of binding buffer, and then $5 \mu \mathrm{L}$ of Annexin V-FITC and $10 \mu \mathrm{L}$ of PI were added and incubated for $15 \mathrm{~min}$ in the dark at room temperature. Cell apoptosis was analyzed with a flow cytometer (BD Bioscience, San Jose, CA, USA) according to the manufacturer's instruction. 


\subsection{Enzyme-Linked Immunosorbent Assay (ELISA)}

C2C12 cell supernatant or skeletal muscle tissues was collected, and then the levels of inflammatory cytokines TNF- $\alpha$, IL- $1 \beta$ and IL- 6 were determined by the commercial ELISA kits purchased from R\&D systems according to the manufacturer's instructions.

\subsection{Glucose uptake assay}

Glucose uptake was measured by using a fluorescent $\mathrm{D}$-glucose analogue 2-NBDG (2-(N-(7-nitrobenz-2-oxa-1,3-diazol-4-yl) amino)-2-deoxyglucose, Sigma-Aldrich, St. Louis, MO, USA) as previously described (Kwak et al., 2017). Briefly, C2C12 myotubes in 96-well black plates were incubated with serum-free DMEM containing 2-NBDG $(10 \mu \mathrm{M})$ in the presence or absence of insulin $(1 \mu \mathrm{g} / \mathrm{mL})$ for $30 \mathrm{~min}$. After washing with PBS, cells were lysed with lysis buffer $(0.1 \mathrm{M}$ potassium phosphate, $1 \%$ Triton X-100, $\mathrm{pH}$ 10) for 10 min with shaking in the dark. DMSO was then added with shaking and allowed to react for $20 \mathrm{~min}$. 2-NBDG uptake was determined by measuring fluorescence by using a fluorescent microplate reader at an excitation wavelength of $466 \mathrm{~nm}$ and an emission wavelength of $550 \mathrm{~nm}$.

\subsection{Animal experiments}

Six-week-old C57BL/6J male mice were obtained from the Laboratory Animal Center of West China Hospital, Sichuan University, and maintained on standard light-dark cycle $(12 \mathrm{~h}$ light/dark cycle) and temperature $\left(22-25^{\circ} \mathrm{C}\right)$ conditions with free access to food and water. $\mathrm{C} 57 \mathrm{BL} / 6 \mathrm{~J}$ mice were randomly divided into four groups ( $\mathrm{n}=10$ per group). Mice received a standard chow diet (10\% kcal from fat. Panlab; Barcelona, Spain) (STD group) or a high-fat diet (60\% kcal from fat. Panlab; Barcelona, Spain) (HFD group) for 12 weeks. Then HFD-fed mice were treated with a daily oral gavage of $1 \mu \mathrm{g} / \mathrm{kg} /$ day VD3 for additional 6 weeks (HFD + VD3 group). The HFD-fed mice were subjected to aerobic interval training (AIT) for additional 6 weeks (HFD + AIT group). Mice run on rodent treadmill with no gradient. and the training program was $10 \mathrm{~m} / \mathrm{min}$ running for $10 \mathrm{~min}$, $25 \mathrm{~m} / \mathrm{min}$ running for $7 \mathrm{~min}$, and $15 \mathrm{~m} / \mathrm{min}$ running for $3 \mathrm{~min}$; and the training time was $60 \mathrm{~min} /$ day alternated with the above three protocols for 5 days/week. After this period, the mice were euthanized. The skeletal muscles were collected, frozen in liquid nitrogen immediately, and stored at $-80^{\circ} \mathrm{C}$. And blood samples were collected, and commercial kits were used to measure the levels of glucose (Spinreact; Barcelona, Spain), insulin (Milliplex, Millipore; Billerica, MA, USA), and triglycerides (Spinreact; Barcelona, Spain) in plasma. All animal experiments in this study were approved by the Animal Ethics Committee of West China Hospital, Sichuan University.

\subsection{Analysis of the cross-sectional area of muscle fibers}

Gastrocnemius muscle of rats was fixed in $4 \%$ paraformaldehyde in $0.1 \mathrm{M}$ phosphate buffer solution ( $\mathrm{pH} 7.4$ ), and then embedded in paraffin and sliced. Paraffin sections were stained with hematoxylin and eosin (H\&E) using a standard protocol. The muscle fiber cross-sectional area was evaluated in muscle sections $(5 \mu \mathrm{m})$ under a Leica microscope (Leica Microsystems;
Wetzlar, Germany). The cross-sectional area of muscle fibers was analyzed by using ImageJ software (NIH, Bethesda, USA).

\subsection{Glucose Tolerance Tests (GTT)}

On week 18, the glucose tolerance test (GTT) was performed to evaluate insulin sensitivity. Briefly, after fasting overnight, mice received $2 \mathrm{~g} / \mathrm{kg}$ body weight of glucose by intraperitoneal injection. Blood was collected from tail veins at $0,30,60,90$ and $120 \mathrm{~min}$ and blood glucose concentrations were measured. The data were plotted as blood glucose concentrations over time. The area under the curve (AUC) was determined as a measure of glucose intolerance.

\subsection{Statistical analysis}

Data analysis was performed with SPSS version 22.0 software. Experimental results from three times independent experiments were presented as mean \pm standard deviation (SD). Student's $\mathrm{t}$-test was performed for the comparison between two groups, and analysis of variance (ANOVA) was performed for comparison among groups. $P<0.05$ was considered to be statistically significant.

\section{Results}

\subsection{VD3 improved cell viability and increased VDR expression in C2C12 myocytes}

To explore the role of VD in skeletal muscle cells, C2C12 cells were treated with PA to induce ER stress and inflammation model, and then incubated with different concentrations of VD3. CCK-8 assay indicated that $\mathrm{C} 2 \mathrm{C} 12$ cell viability decreased obviously after PA treatment, and VD3 improved the impaired cell viability induced by PA in a dose-dependent manner, and its protective effect on cell viability was most obvious at a maximum concentration of $100 \mathrm{nM}$ (Figure 1A). Therefore, $100 \mathrm{nM}$ was selected as the VD3 treatment condition in subsequent experiments. Moreover, it's observed that VDR expression level was increased by VD3 in a dose-dependent manner in C2C12 muscle cells (Figure 1B, C).

\subsection{VD3 ameliorates ER stress, apoptosis, inflammation and glucose uptake in C2C12 myocytes}

PA-treated C2C12 cells were incubated with $100 \mathrm{nM} \mathrm{VD3}$ to investigate the role of VD in skeletal muscle cell functions. We found that $\mathrm{C} 2 \mathrm{C} 12$ cell viability (Figure $2 \mathrm{~A}$ ) was reduced and cell apoptosis (Figure 2B, C) was increased after PA treatment, while VD3 enhanced cell viability and attenuated cell apoptosis in $\mathrm{C} 2 \mathrm{C} 12$ cells. Furthermore, Western blotting showed that PA treatment increased the expression levels of ER stress marker proteins GRP78, CHOP and ATF6, which were reduced by VD3 treatment (Figure 2D-G). ELISA results indicated that PA treatment promoted the secretion of inflammatory cytokines including TNF- $\alpha$, IL-1 $\beta$ and IL- 6 in C2C12 cells, while VD3 inhibited the secretion of TNF- $\alpha$, IL- $1 \beta$ and IL- 6 (Figure $2 \mathrm{H}-\mathrm{J}$ ). Besides, we found that insulin-stimulated glucose uptake was decreased by PA, but VD3 markedly blocked this effect of PA (Figure 2K). These results indicated that VD3 ameliorated PA-induced apoptosis, ER stress, inflammation and glucose uptake in $\mathrm{C} 2 \mathrm{C} 12$ myocytes. 

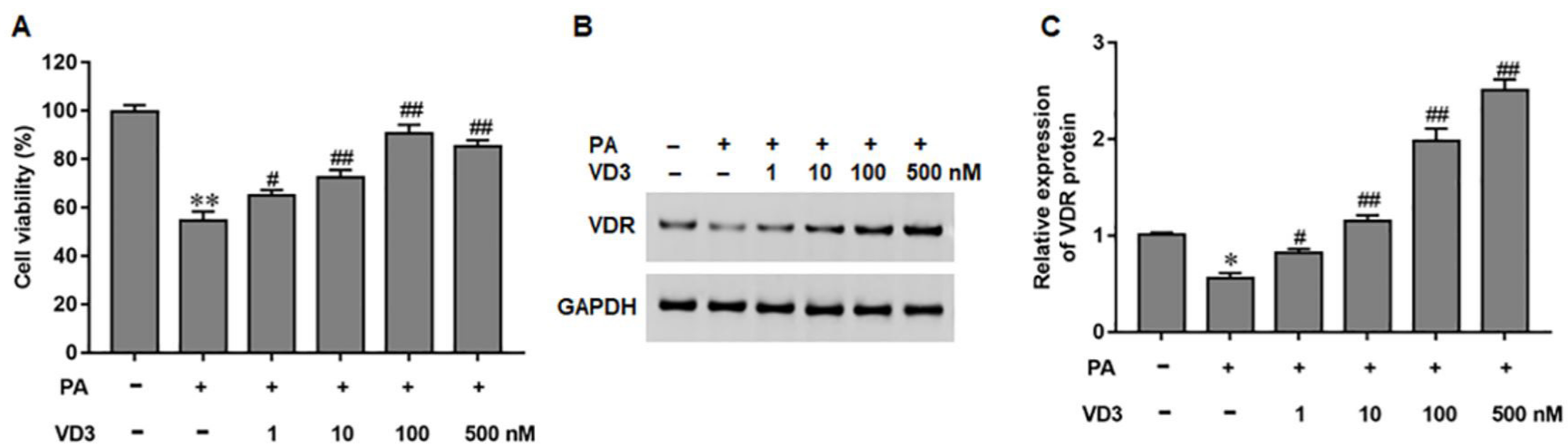

Figure 1. VD3 improved cell viability and increased VDR expression in C2C12 myocytes. C2C12 cells were treated with $0.5 \mathrm{mM}$ PA to induce ER stress and inflammation model, and then incubated with different concentrations (0, 1, 10, 100 and $500 \mathrm{nM})$ of VD3. (A) C2C12 cell viability was measured by using CCK-8 assay; $(B, C)$ Western blotting was performed to evaluate the expression of VDR protein. Data were presented as mean $\pm \mathrm{SD}$. $\mathrm{N}=6,{ }^{\star} P<0.05$ and ${ }^{\star *} P<0.01$, compare with the first group. ${ }^{*} P<0.05$ and ${ }^{\# *} P<0.01$, compare with the second group.

\subsection{VDR overexpression ameliorates ER stress, apoptosis, inflammation and glucose uptake in C2C12 myocytes}

To explore the role of VDR in skeletal muscle cells, VDR overexpression plasmid pcDNA-VDR was transfected into $\mathrm{C} 2 \mathrm{C} 12$ cells. Western blotting implied that transfection of pcDNA-VDR increased VDR expression in C2C12 cells (Figure 3A, B). Moreover, VDR overexpression enhanced cell viability (Figure 3C) and decreased cell apoptosis (Figure 3D, E) in PA-treated C2C12 cells. Additionally, PA treatment increased the expression of ER stress marker proteins GRP78, CHOP and ATF6 (Figure 3F-I), and inflammatory cytokines TNF- $\alpha$, IL-1 $\beta$ and IL-6 (Figure 3J-L), whereas VDR overexpression rescued these effects. Besides, VDR overexpression improved the impaired glucose uptake induced by PA (Figure $3 \mathrm{M}$ ). These results demonstrated that VDR overexpression alleviates PA-induced apoptosis, ER stress, inflammation and glucose uptake in C2C12 myocytes.

\subsection{VD3 ameliorates ER stress, apoptosis, inflammation and glucose uptake in C2C12 myocytes by inducing VDR expression}

To explore whether VD3 exerts its functions by regulating VDR expression, PA-treated C2C12 cells were treated with VD3 alone or together with transfection of si-VDR. Western blotting showed that VD3 treatment increased VDR expression, while transfection of si-VDR decreased VDR expression in PAtreated C2C12 cells (Figure 4A, B). Moreover, it was observed that VD3 promoted cell viability (Figure $4 \mathrm{C}$ ) and suppressed apoptosis (Figure 4D, E) in PA-treated C2C12 cells, which were then reversed by VDR knockdown. And VD3 treatment attenuated the expression levels of ER stress marker proteins (Figure 4F-I) and inflammatory cytokines (Figure 4J-L) in C2C12 cells, while VDR knockdown reversed these effects. which were reduced by VD3 treatment. In addition, we found that VD3 rescued insulin-stimulated glucose uptake in PA-treated $\mathrm{C} 2 \mathrm{C} 12$ cells, which was blocked by VDR knockdown (Figure 4M). These results revealed that VD3 alleviates PA-induced apoptosis, ER stress, inflammation and glucose uptake by promoting VDR expression in $\mathrm{C} 2 \mathrm{C} 12$ myocytes.

\subsection{AMPK/SIRT1 activation is involved in the protective effects of VD3 on C2C12 myocytes}

AMPK/SIRT1 activation is a known key mediator of ER stress and insulin resistance in myotube. AMPK signaling inhibitor Compound $\mathrm{C}$ was used to explore whether AMPK/ SIRT1 activation is involved in the protective effects of VD3 on $\mathrm{C} 2 \mathrm{C} 12$ myocytes. Western blotting indicated that the expression of p-AMPK and SIRT1 proteins was reduced by PA treatment, whereas VD3 increased their expression, which was reversed by Compound C (Figure 5A, B). Moreover, we found that VD3 promoted cell viability (Figure 5C) and suppressed apoptosis (Figure 5D, E) in PA-treated C2C12 cells, while Compound C treatment reversed these effects. And VD3 treatment attenuated the expression levels of ER stress marker proteins (Figure 5F-I) and inflammatory cytokines (Figure 5J-L) in C2C12 cells, and VDR knockdown reversed these effects, which were then reduced by Compound C. These results demonstrated that AMPK/SIRT1 activation is involved in the protective effects of VD3 on C2C12 myocytes.

\subsection{VD3 alleviates skeletal muscle loss and insulin resistance in mice}

We observed that myofiber cross-sectional area was decreased in HFD group, and VD3 treatment and AIT both prevented HFD-induced decline in myocyte area (Figure 6A). Moreover, GTT showed that mice in HFD group became glucose intolerant and showed a significant increase in the area under the curve (AUC) compared with STD-fed mice, while VD3 and AIT treatment both improved this effect (Figure 6B, C). HFD feeding raised plasma levels of glucose (Figure 6D), insulin (Figure 6E) and triglyceride (Figure 6F), which were all suppressed by VD3 and AIT treatment. Additionally, the expression levels of ER stress 

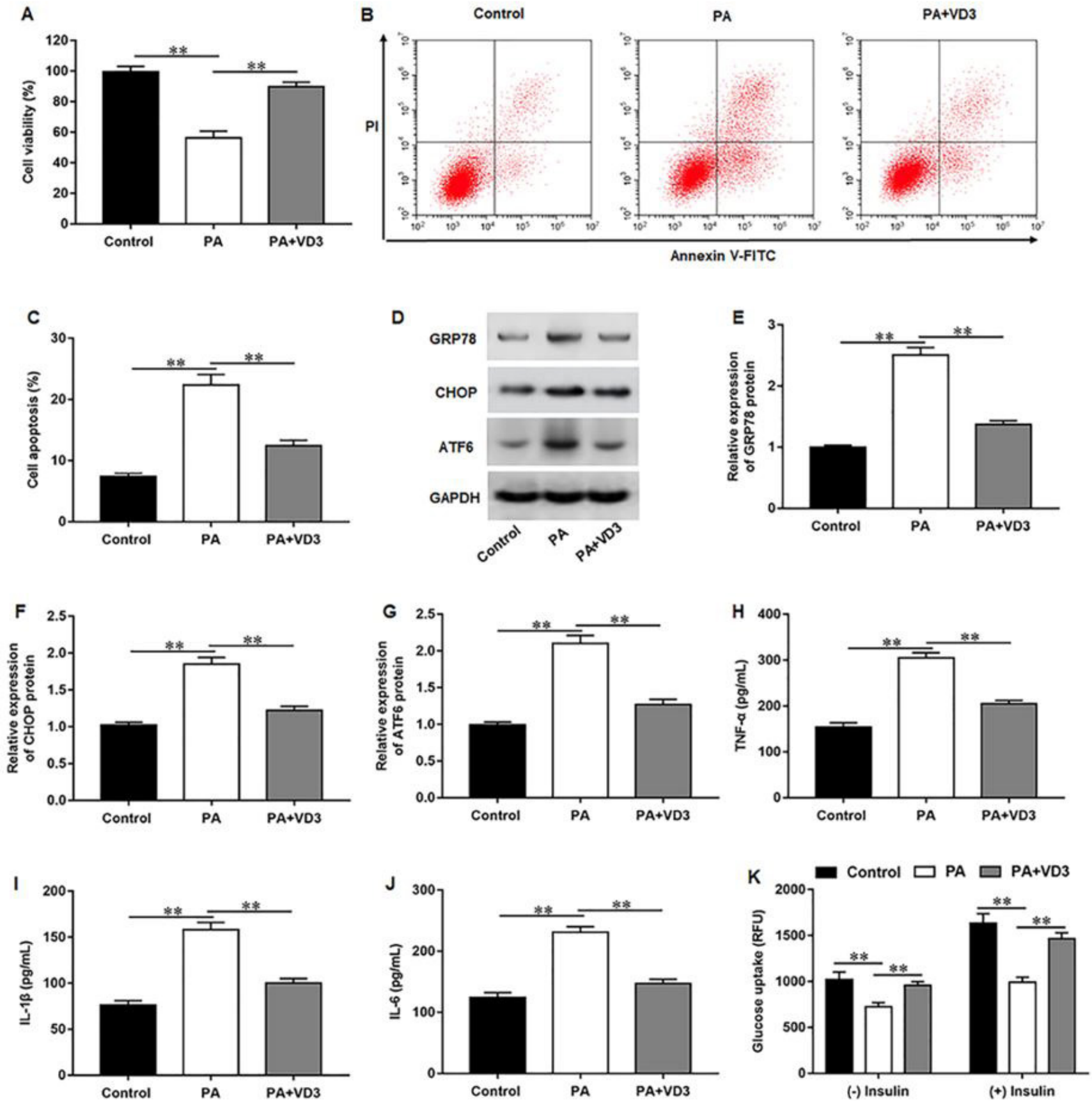

Figure 2. VD3 ameliorates ER stress, apoptosis, inflammation and glucose uptake in C2C12 myocytes. PA-treated C2C12 cells were incubated with $100 \mathrm{nM}$ VD3. (A) C2C12 cell viability was evaluated with CCK-8 assay; (B, C) Flow cytometry assay was conducted to detect C2C12 cell apoptosis; (D-G) The expression of GRP78, CHOP and ATF6 proteins was examined with Western blotting; (H-J) The levels of TNF- $\alpha$, IL-1 $\beta$ and IL-6 in cell culture supernatant were detected with ELISA kits; (K) Glucose uptake assay was performed to detect the glucose uptake in C2C12 cells. Data were presented as mean $\pm \mathrm{SD} . \mathrm{N}=6,{ }^{* *} P<0.01$.

marker proteins (Figure 6G, H) and inflammatory cytokines (Figure 6I-6K) were increased in the HFD-fed mice, while VD3 and AIT treatment rescued these effects. These results indicated that VD3 and AIT both alleviate skeletal muscle loss and insulin resistance in mice, and the protective effect of VD3 is more obvious than AIT.

\subsection{Overview of study design and flowchart}

The overview of study design and flowchart was shown in Figure 7. This study explored the roles and mechanisms of VD/VDR signaling in skeletal muscle cell injury, and skeletal muscle loss and insulin resistance in mice from in vitro and in vivo experiments. 
A

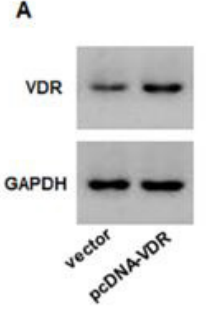

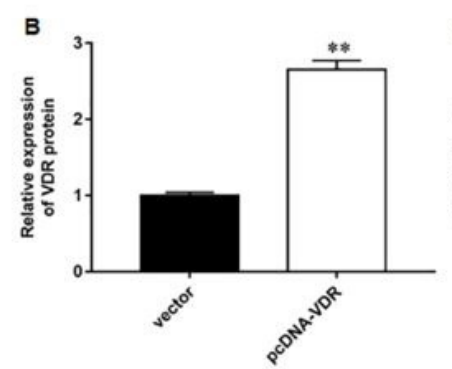

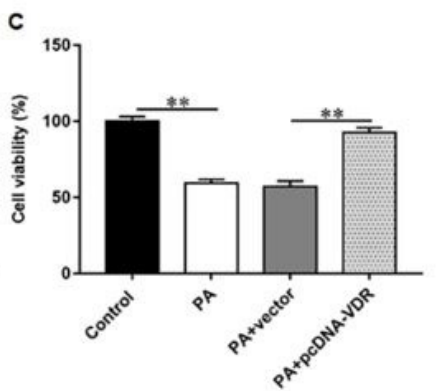

E
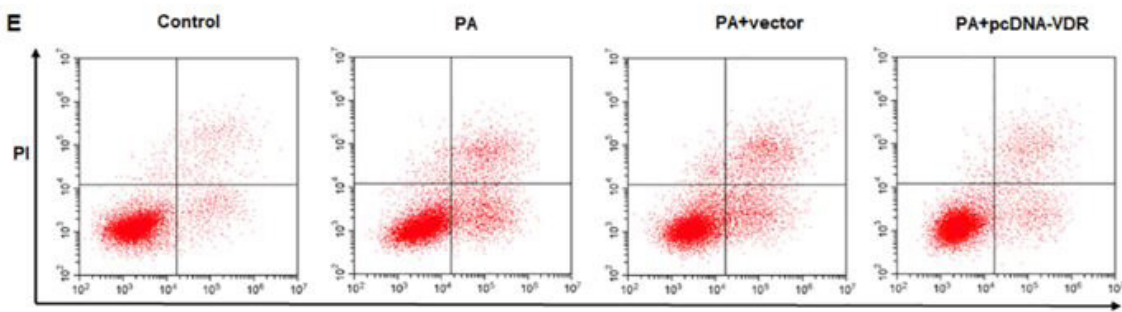

Annexin V-FITC
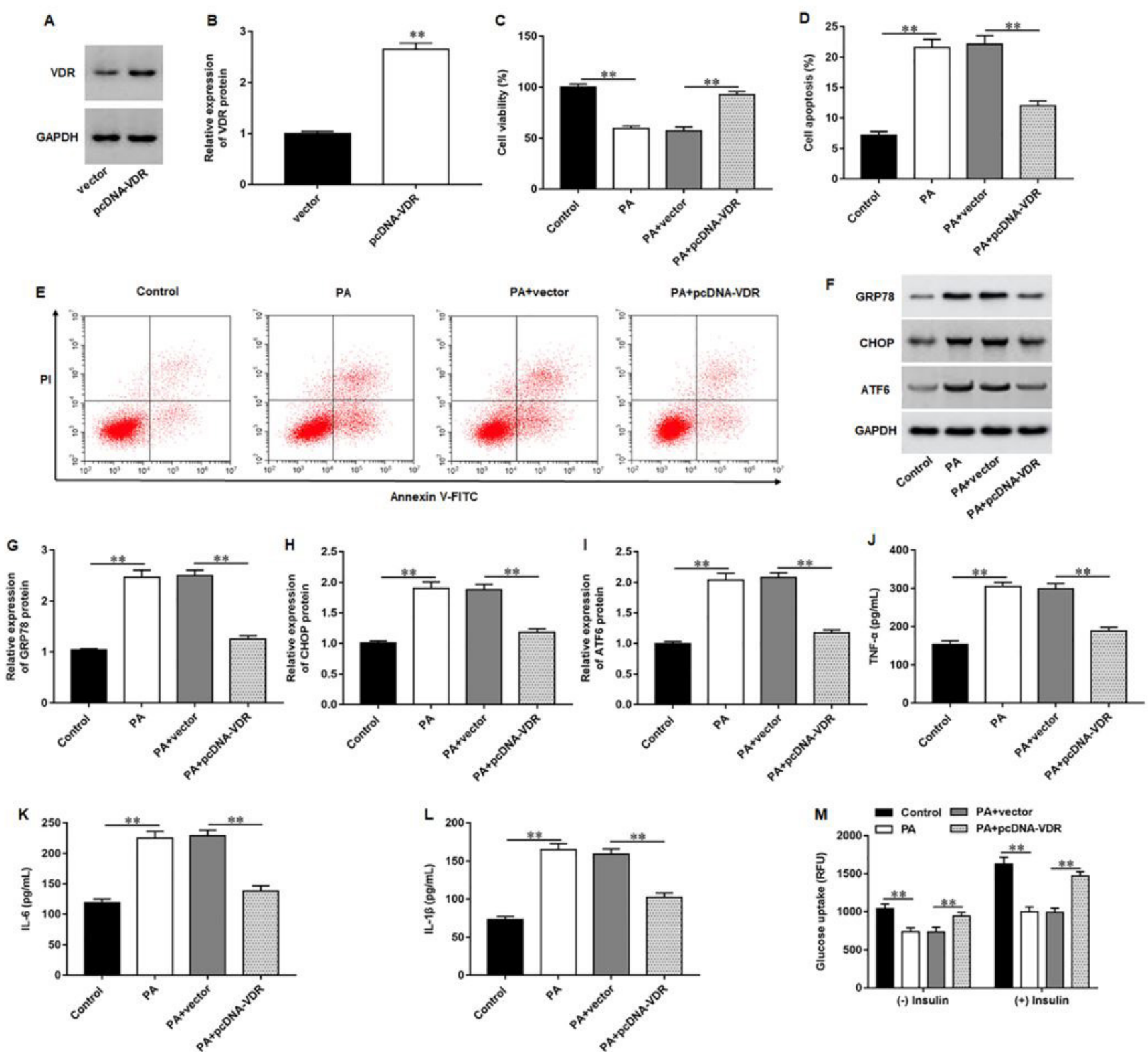

Figure 3. VDR overexpression ameliorates ER stress, apoptosis and inflammation in C2C12 myocytes. pcDNA-VDR (20 nM) and its negative control $(20 \mathrm{nM})$ were transfected into C2C12 cells, respectively. (A, B) Western blotting was performed to evaluate the expression of VDR expression; (C) C2C12 cell viability was measured by using CCK-8 assay; (D, E) C2C12 cell apoptosis was measured by using flow cytometry; (F-I) The expression of GRP78, CHOP and ATF6 proteins was examined with Western blotting; (J-L) The levels of TNF- $\alpha$, IL-1 $\beta$ and IL-6 in cell culture supernatant were detected with ELISA; (M) Glucose uptake assay was used to detect glucose uptake in C2C12 cells. Data were presented as mean $\pm \mathrm{SD} . \mathrm{N}=6,{ }^{* *} \mathrm{P}<0.01$.

\section{Discussion}

Increasing studies have revealed a number of foods contains high levels of bioactive compounds play protective roles in glucose-lipid metabolism disorders. For instance, a beverage composed by tropical fruits and yacon showed antioxidant and prebiotic effects on alloxan-induced diabetic rats, which contains high levels of fructooligosaccharides, gallic acid and ascorbic acid (Dionisio et al., 2020). Grape processing by-products have substantial amounts of fibers and phenolic compounds had hypolipidemic and antioxidant effects on high-fat/cholesterol diet-induced hyperlipidemic hamsters (Ishimoto et al., 2020). VD is mainly derived from animal foods such as animal liver, cod-liver oil, yolk and cream. The present study investigated the effects of VD on skeletal muscle health and insulin resistance in high-fat diet fed mice.

The improved effects of VD on skeletal muscle strength, function and metabolism have been proposed, which was functioned through regulation of protein synthesis, myogenesis, mitochondrial 

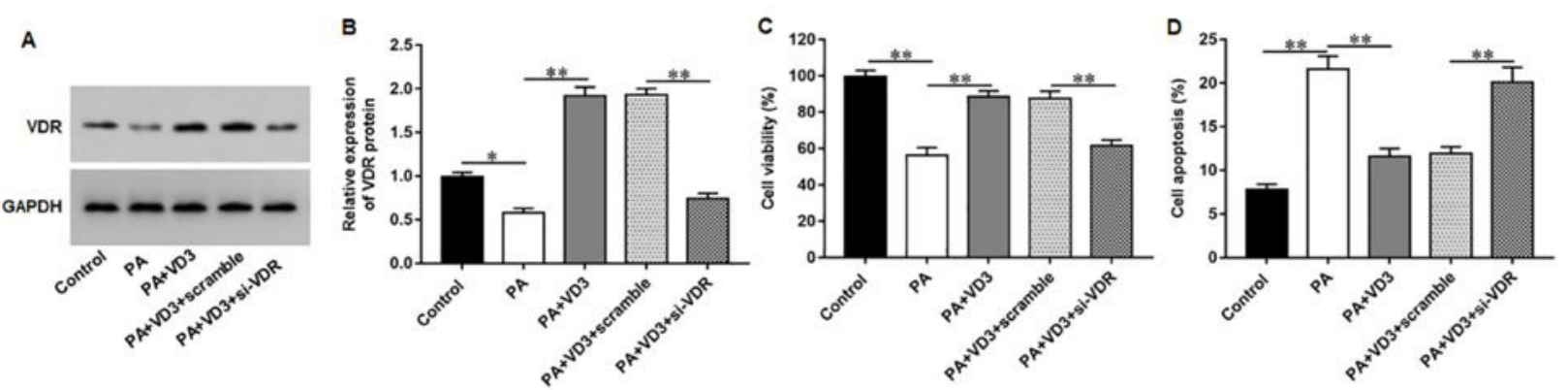

E
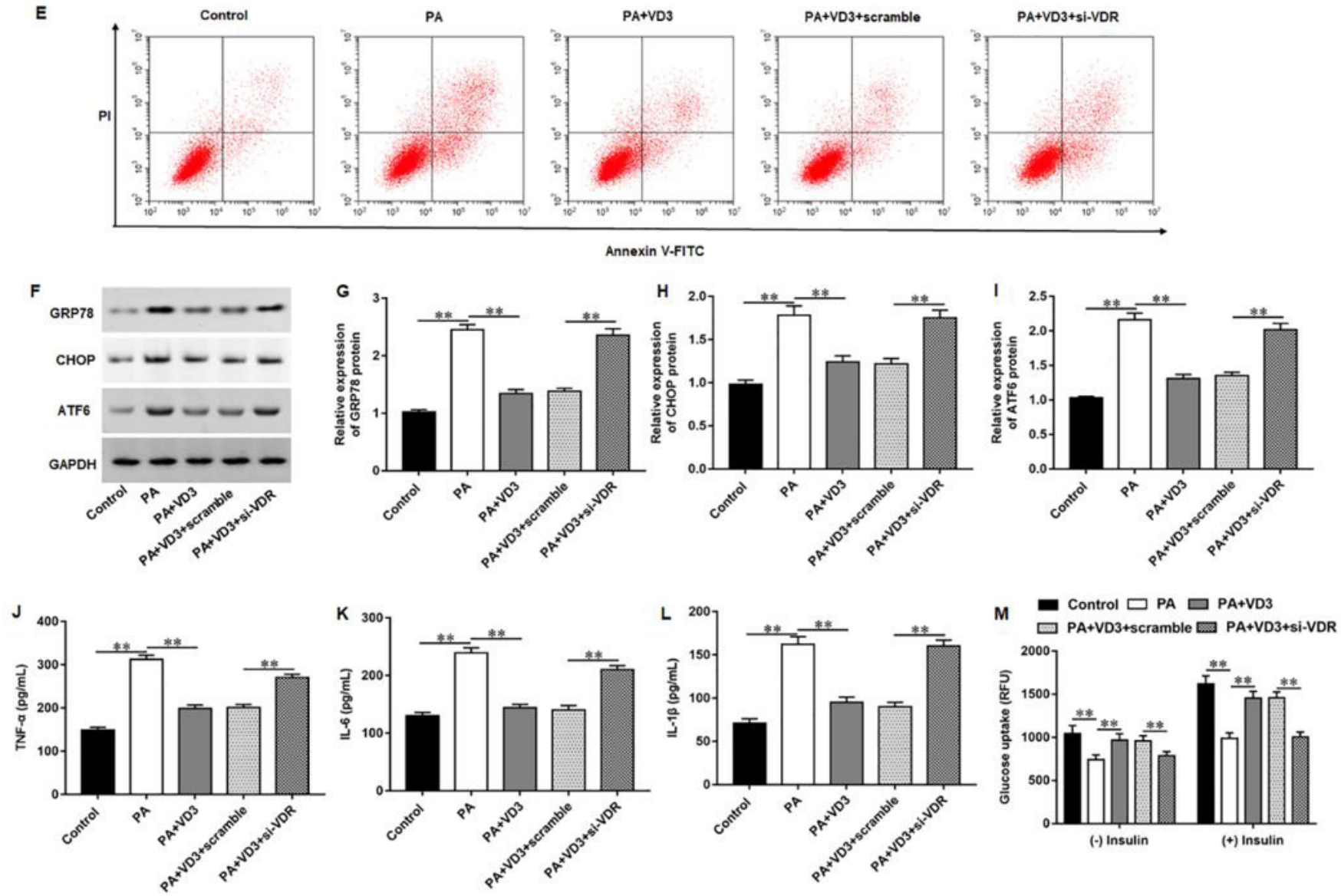

Figure 4. VD3 ameliorates ER stress, apoptosis, inflammation and glucose uptake by promoting VDR expression in C2C12 myocytes. PA-treated $\mathrm{C} 2 \mathrm{C} 12$ cells were treated with $100 \mathrm{nM}$ VD3 alone or together with transfection of si-VDR $(30 \mathrm{nM})$. (A, B) The expression of VDR protein was detected by using Western blotting; (C) CCK-8 assay was performed to measure C2C12 cell viability; (D, E) C2C12 cell apoptosis was measured by using flow cytometry; (F-I) The expression of GRP78, CHOP and ATF6 proteins was examined by using Western blotting; (J-L) The levels of TNF- $\alpha$, IL-1 $\beta$ and IL- 6 in cell supernatant were detected by using ELISA; (M) Glucose uptake assay was performed to detect the glucose uptake in $\mathrm{C} 2 \mathrm{C} 12$ cells. Data were presented as mean $\pm \mathrm{SD}$. N $=6,{ }^{\star} P<0.05,{ }^{\star \star} P<0.01$.

activity, muscle regeneration and glucose metabolism. VD/VDR signaling has been proved to be closely related with skeletal muscle functions. A previous study illustrated that high-dose vitamin $\mathrm{D}$ administration attenuate the progression of obesity and improve skeletal muscle function in obese p62-deficient mice (Kim et al., 2020). VD supplementation in a mice model of high fat-high sugar diet-induced insulin resistance reduced body weight, improved impaired muscle insulin signaling, and reverted myosteatosis evoked by the diet (Benetti et al., 2018).
In addition, VDR knockdown inhibited differentiation and induced myogenic dysregulation in $\mathrm{C} 2 \mathrm{C} 12$ cells in vitro, and VDR knockdown mice present a reduction of total protein content and low myofiber area, resulting in skeletal muscle atrophy (Bass et al., 2021). In this study, we found that treatment of VD3 and overexpression of VDR both could ameliorate PA-induced ER stress, apoptosis, inflammation and glucose uptake in $\mathrm{C} 2 \mathrm{C} 12$ myocytes, and alleviated HFD-induced skeletal muscle loss and insulin resistance in mice. VD exerts its genomic 


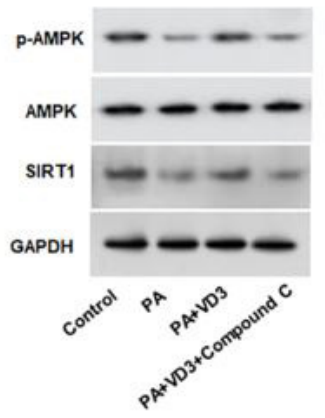

B $=$ Control $\square \mathrm{PA} \square \mathrm{PA}+\mathrm{VD} 3$

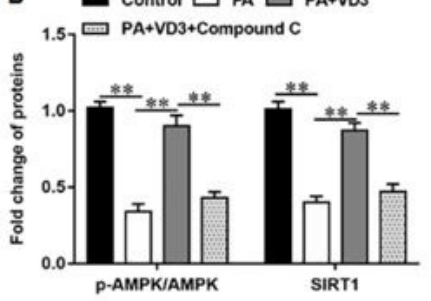

c

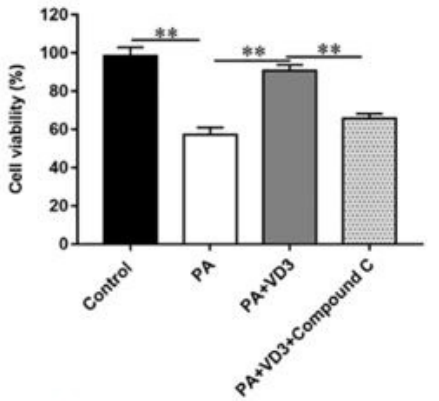

D

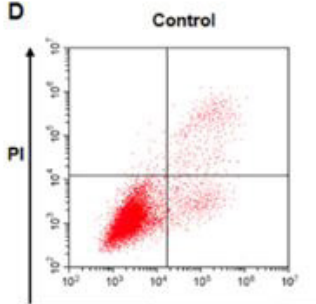

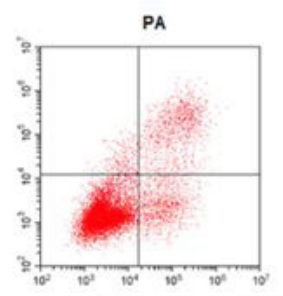
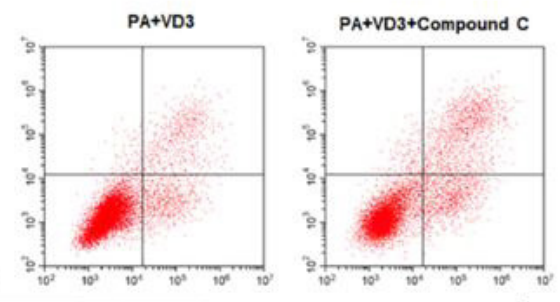

PA+VD3+Compound C

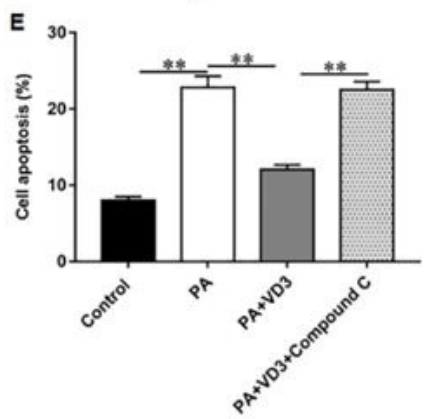

G
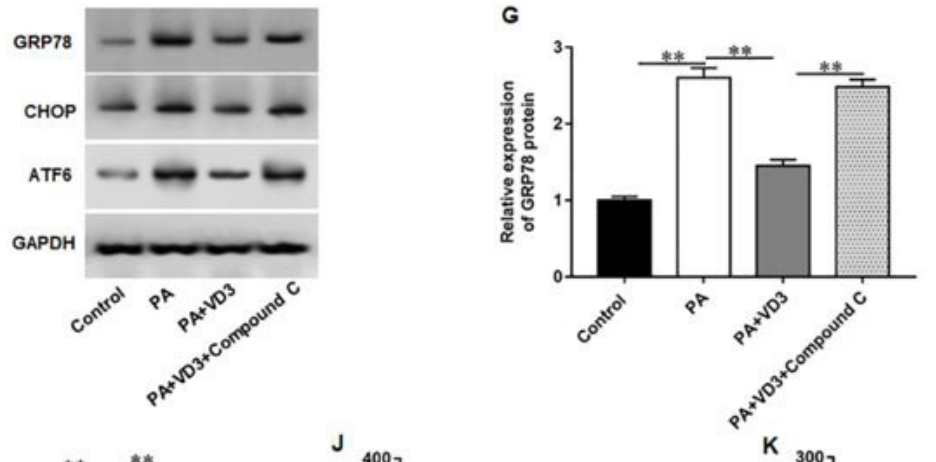

H
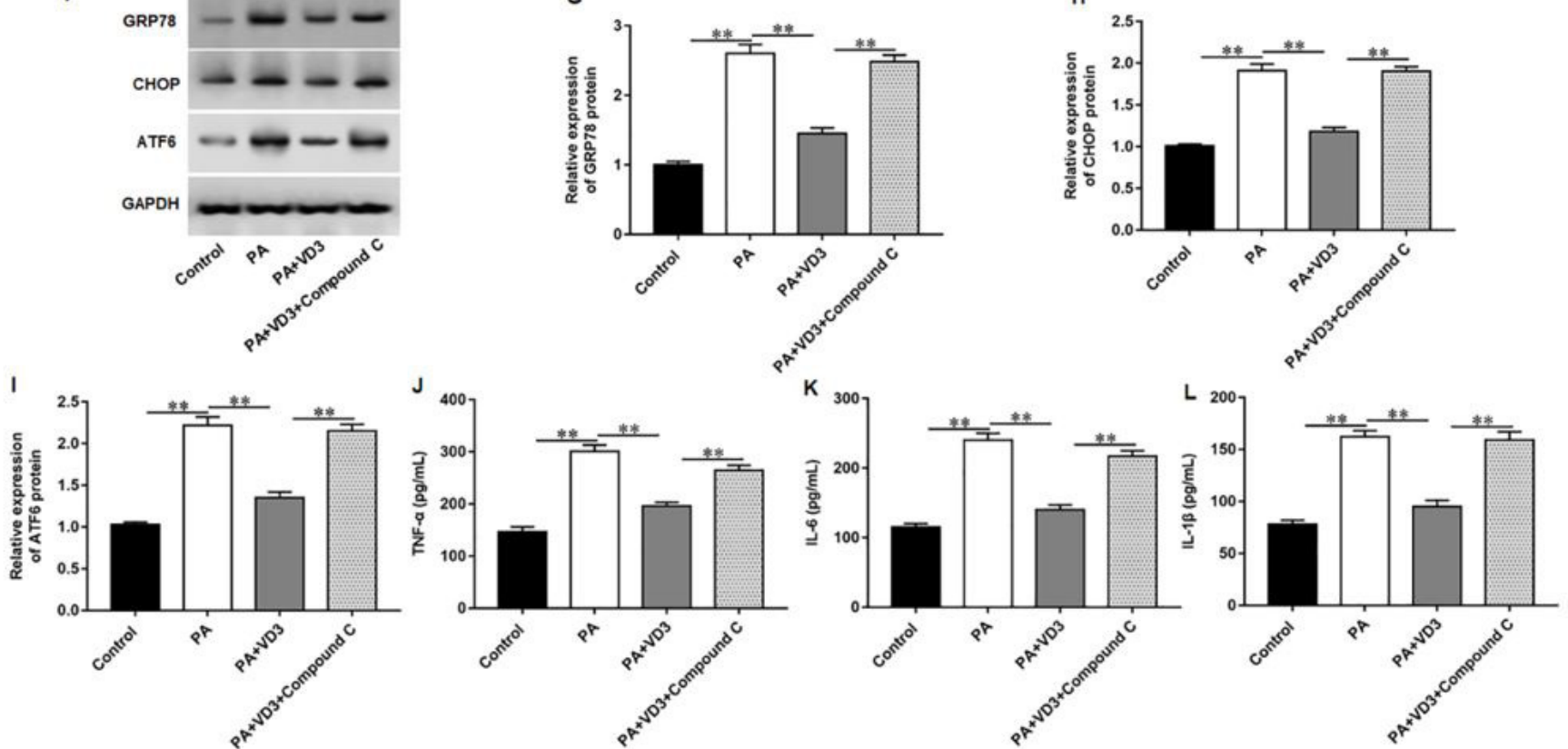

Figure 5. AMPK/SIRT1 activation is involved in the protective effects of VD3 on C2C12 myocytes. PA-treated C2C12 cells were treated with 100 nM VD3 alone or together with AMPK signaling inhibitor Compound C (50 nM). (A, B) The expression of VDR protein was detected by using Western blotting; (C) C2C12 cell viability was detected with CCK-8 assay; (D, E) C2C12 cell apoptosis was measured by using flow cytometry; (F-I) Western blotting was performed to examine the expression of GRP78, CHOP and ATF6 proteins; (J-L) The levels of TNF- $\alpha$, IL-1 $\beta$ and IL-6 in cell culture supernatant were detected by using ELISA. Data were presented as mean $\pm \mathrm{SD}$. $\mathrm{N}=6,{ }^{*} P<0.01$.

functions through the generally expressed VDR. It was previously confirmed that VD3 treatment increased intramuscular VDR mRNA expression in human primary myoblasts, and supplementation with VD3 for 16 weeks resulted in a persistent increase in VDR gene expression in muscle tissue biopsies (Pojednic et al., 2015). Moreover, VD3-mediated upregulation of VDR expression contributed to the proliferation and differentiation in skeletal muscle cell. amelioration of palmitate-induced impairment of insulin signaling in mouse skeletal muscle cells (Irazoqui et al., 2014). Our study demonstrated that VD3 stimulated VDR expression in $\mathrm{C} 2 \mathrm{C} 12$ myocytes, and reverse experiments showed that VDR knockdown via siRNA reversed the protective effects of VD on skeletal muscle cells, indicating that VD3 exerts it functions via regulation of VDR in skeletal muscle cells. 

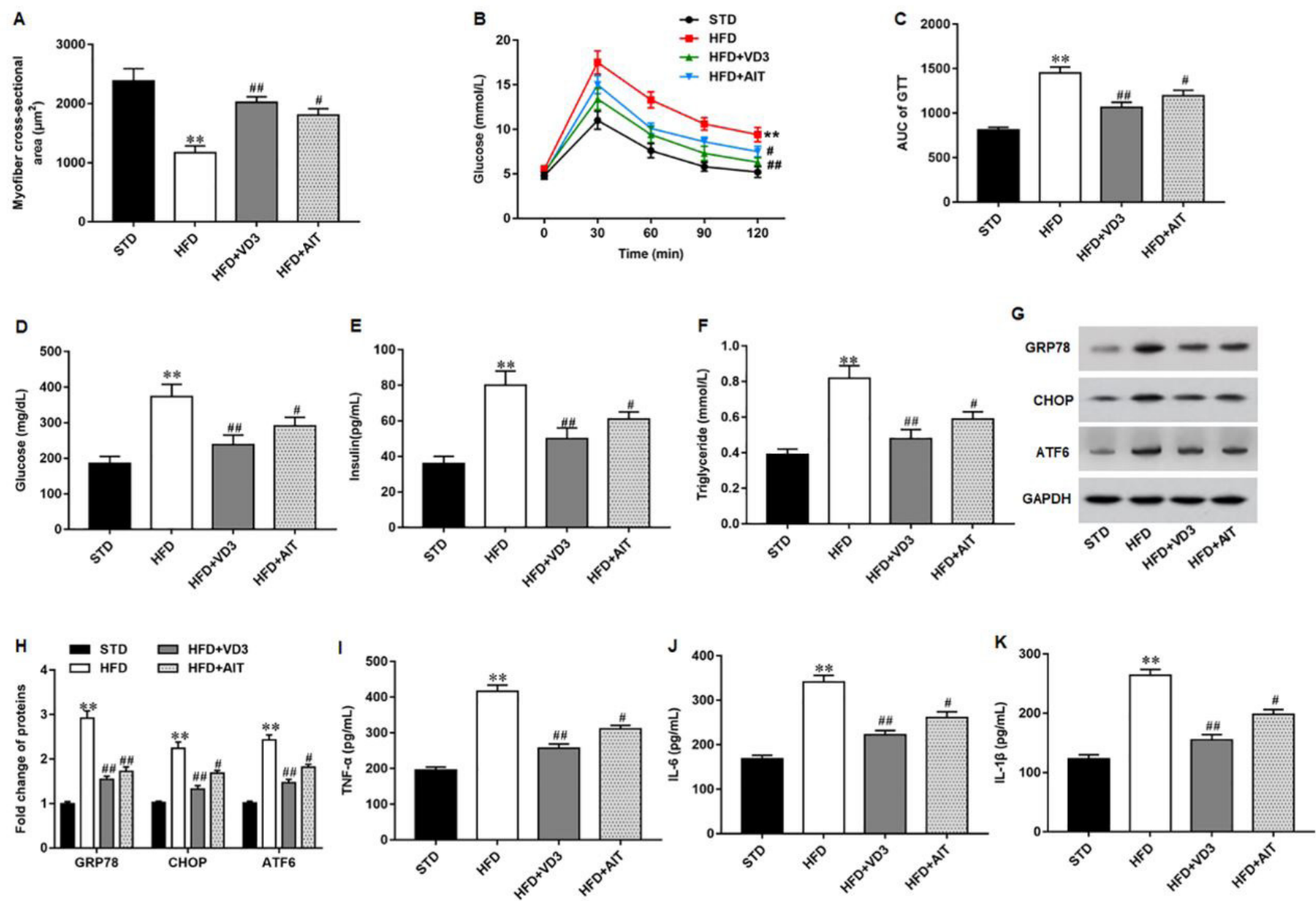

Figure 6. VD3 alleviates skeletal muscle loss and insulin resistance in mice. C57BL/6J male mice were randomly divided into four groups ( $\mathrm{n}=10$ per group): STD group (mice received a standard chow diet for 12 weeks); HFD group (mice received a a high-fat diet for 12 weeks); HFD+VD3 group (mice in HFD group were treated with a daily oral gavage of $1 \mu \mathrm{g} / \mathrm{kg} /$ day VD3 for additional 6 weeks). HFD+AIT (mice in HFD group were subjected to aerobic interval training for additional 6 weeks). (A) The relative cross-sectional area of skeletal muscle fibers from each group after 18 weeks of experimentation. Scale bar $=100 \mu \mathrm{m}$; (B) Glucose tolerance test (GTT) was performed at week 18; (C) The area under the curve (AUC) of GTT; (D-F) The plasma levels of glucose, insulin and triglyceride were measured with commercial kits; (G, H) Western blotting was performed to examine the expression of GRP78, CHOP and ATF6 proteins; (I-K) The levels of TNF- $\alpha$, IL-1 $\beta$ and IL- 6 in cell culture supernatant were detected by using ELISA. Data were presented as mean \pm SD. ${ }^{*} P<0.01$, compare with the STD group. ${ }^{\#} P<0.05$ and ${ }^{\#} P<0.01$, compare with the HFD group.

Excessive ER stress has been implicated as key mechanism for the apoptosis, inflammation and insulin sensitivity in skeletal muscle cells, which suggests ER stress be considered major targets for preventing skeletal muscle loss and insulin resistance. Increasing studies have reported VD-mediated inhibition of ER stress play key roles in various diseases. VD3 treatment decreased ER stress-induced inflammatory response in mammary epithelial cells (Wen et al., 2020). Moreover, VD treatment promoted proliferation, inhibited apoptosis, reduced the levels of endogenous markers of ER stress in human umbilical vein endothelial cells, and improved the impaired wound healing in diabetic mice by suppressing ER stress (Yuan et al., 2018). VD analogs prevent tunicamycin-induced ER stress and oxidative stress in human umbilical endothelial cells, and inhibition of VDR expression via siRNA reversed the protective effects of $\mathrm{VD}$, indicating that $\mathrm{VD} /$
VDR signaling play protective roles in vascular endothelial cells by inhibiting ER stress and oxidative stress (Haas et al., 2016). In the present study, we found that VD3/VDR could reduce PA-induced elevated levels of ER stress marker proteins, and then ameliorate apoptosis, inflammation and glucose uptake in C2C12 myocytes, as well as HFD-induced skeletal muscle loss and insulin resistance in mice.

Some studies have shown that VD-mediated activation of AMPK/SIRT1 provides potent protective effects on skeletal muscle. For instance, a current study revealed that the activation of AMPK and SIRT1 might be involved in the inhibitory effect of VD on tertiary butyl-hydrogen peroxide-induced oxidative stress and mitochondrial dynamics in C2C12 skeletal muscle cells (Chang, 2019). VD-mediated activation of AMPK/SIRT1 pathway ameliorates PA-induced muscle fat accumulation and mitochondrial 

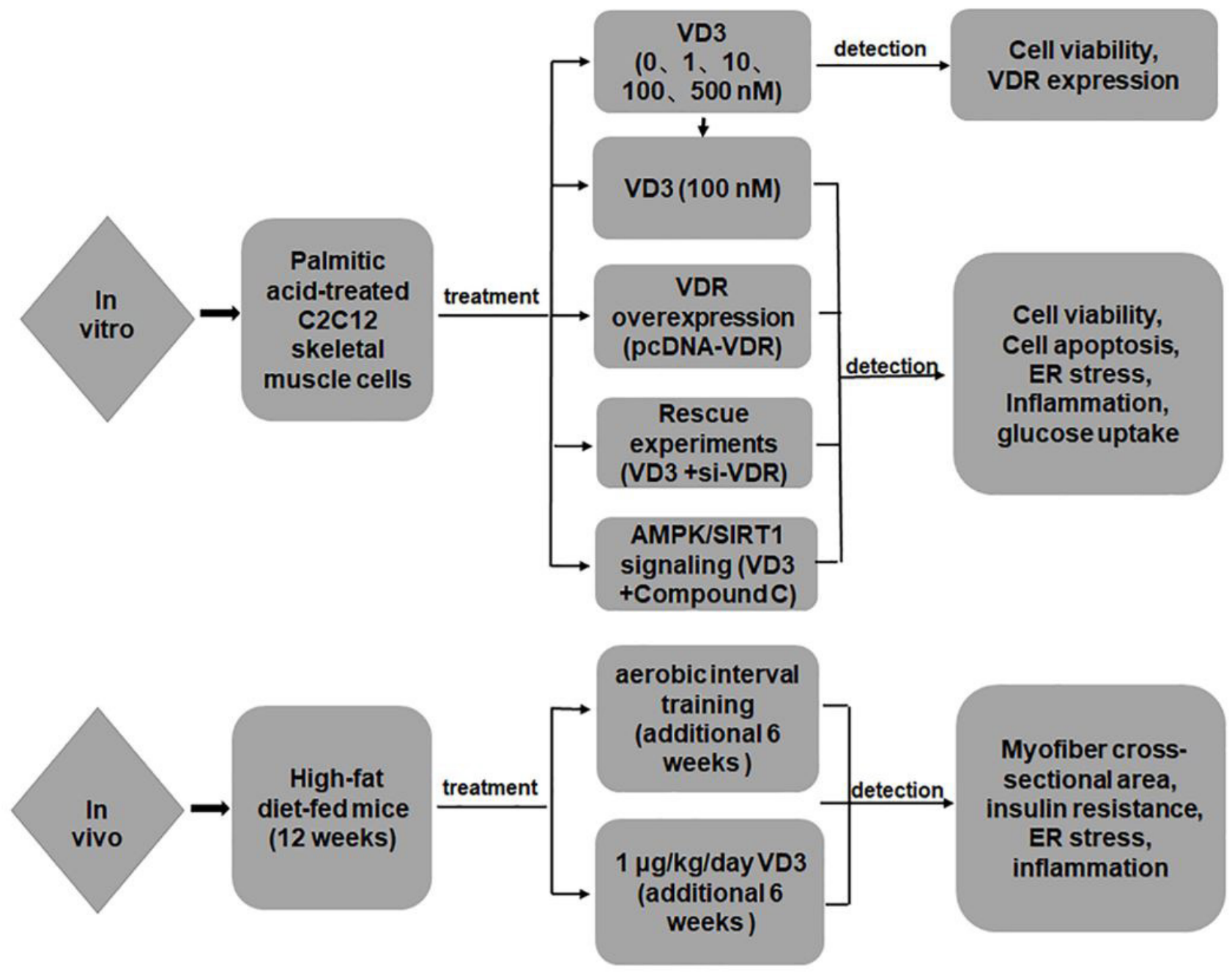

Figure 7. Overview of study design and flowchart. This study explored the roles and mechanisms of VD/VDR signaling in skeletal muscle cell injury, and skeletal muscle loss and insulin resistance in mice from in vitro and in vivo experiments.

dysfunction in C2C12 skeletal muscle cells (Chang \& Kim, 2019). More importantly, several recent studies have shown that AMPK and SIRT1 activation play a protective role in skeletal muscle by suppressing ER stress. Oleate treatment improved PAinduced inflammation insulin resistance in skeletal muscle cells through suppression of the ER stress via an AMPK-dependent mechanism (Salvadó et al., 2013). Developmental endothelial locus-1 attenuates PA-induced and HFD-induced ER stress and insulin resistance in skeletal muscle via SIRT1/SERCA2mediated ER stress inhibition (Sun et al., 2020). Interestingly, our results showed that VD increased the protein levels of p-AMPK and SIRT1 in PA-treated C2C12 myocytes, and VD-mediated activation of AMPK/SIRT1 signaling pathway prevented ER stress, apoptosis, and inflammation.

Taken together, our findings indicated that VD treatment inhibited AMPK/SIRT1-mediated ER stress by increasing VDR expression, and further improved apoptosis, inflammation and glucose uptake in skeletal muscle cells, as well as skeletal muscle loss and insulin resistance in mice.

\section{Conflict of interest}

The authors declare that they have no conflict of interest.

\section{Funding}

The authors declare that no financial support was received.

\section{References}

Bass, J. J., Kazi, A. A., Deane, C. S., Nakhuda, A., Ashcroft, S. P., Brook, M. S., Wilkinson, D. J., Phillips, B. E., Philp, A., Tarum, J., Kadi, F., Andersen, D., Garcia, A. M., Smith, K., Gallagher, I. J., Szewczyk, N. J., Cleasby, M. E., \& Atherton, P. J. (2021). The mechanisms of skeletal muscle atrophy in response to transient knockdown of the vitamin D receptor in vivo. The Journal of Physiology, 599(3), 963979. http://dx.doi.org/10.1113/JP280652. PMid:33258480. 
Benetti, E., Mastrocola, R., Chiazza, F., Nigro, D., D’Antona, G., Bordano, V., Fantozzi, R., Aragno, M., Collino, M., \& Minetto, M. A. (2018). Effects of vitamin D on insulin resistance and myosteatosis in diet-induced obese mice. PLoS One, 13(1), e0189707. http://dx.doi. org/10.1371/journal.pone.0189707. PMid:29342166.

Bosquet, A., Girona, J., Guaita-Esteruelas, S., Heras, M., Saavedra-García, P., Martínez-Micaelo, N., Masana, L., \& Rodríguez-Calvo, R. (2018). FABP4 inhibitor BMS309403 decreases saturated-fatty-acid-induced endoplasmic reticulum stress-associated inflammation in skeletal muscle by reducing p38 MAPK activation. Biochimica et Biophysica Acta. Molecular and Cell Biology of Lipids, 1863(6), 604-613. http:// dx.doi.org/10.1016/j.bbalip.2018.03.004. PMid:29550588.

Chang, E. (2019). 1,25-dihydroxyvitamin D decreases tertiary butylhydrogen peroxide-induced oxidative stress and increases AMPK/ SIRT1 activation in C2C12 muscle cells. Molecules, 24(21), 3903. http://dx.doi.org/10.3390/molecules24213903. PMid:31671915.

Chang, E., \& Kim, Y. (2019). Vitamin D ameliorates fat accumulation with AMPK/SIRT1 activity in C2C12 skeletal muscle cells. Nutrients, 11(11), 2806. http://dx.doi.org/10.3390/nu11112806. PMid:31744213.

Chavez, J. A., Knotts, T. A., Wang, L. P., Li, G., Dobrowsky, R. T., Florant, G. L., \& Summers, S. A. (2003). A role for ceramide, but not diacylglycerol, in the antagonism of insulin signal transduction by saturated fatty acids. The Journal of Biological Chemistry, 278(12), 10297-10303. http://dx.doi.org/10.1074/jbc.M212307200. PMid:12525490.

Chen, M., Li, S., Hao, M., Chen, J., Zhao, Z., Hong, S., Min, J., Tang, J., Hu, M., \& Hong, L. (2020). T-type calcium channel blockade induces apoptosis in $\mathrm{C} 2 \mathrm{C} 12$ myotubes and skeletal muscle via endoplasmic reticulum stress activation. FEBS Open Bio, 10(10), 2122-2136. http:// dx.doi.org/10.1002/2211-5463.12965. PMid:32865339.

Dai, F., Jiang, T., Bao, Y. Y., Chen, G. J., Chen, L., Zhang, Q., \& Lu, Y. X. (2016). Fenofibrate improves high-fat diet-induced and palmitateinduced endoplasmic reticulum stress and inflammation in skeletal muscle. Life Sciences, 157, 158-167. http://dx.doi.org/10.1016/j. lfs.2016.06.008. PMid:27297630.

Dionisio, A. P., Carvalho-Silva, L. B., Vieira, N. M., Wurlitzer, N. J., Pereira, A. C. S., Borges, M. F., Garruti, D. S., \& Araújo, I. S. (2020). Antioxidant and prebiotic effects of a beverage composed by tropical fruits and yacon in alloxan-induced diabetic rats. Food Science and Technology, 40(1), 202-208. http://dx.doi.org/10.1590/fst.34518.

Frontera, W. R., \& Ochala, J. (2015). Skeletal muscle: a brief review of structure and function. Calcified Tissue International, 96(3), 183195. http://dx.doi.org/10.1007/s00223-014-9915-y. PMid:25294644.

Guo, F., Yue, H., Wang, L., Ding, C., Wu, L., Wu, Y., Gao, F., \& Qin, G. (2017). Vitamin D supplement ameliorates hippocampal metabolism in diabetic rats. Biochemical and Biophysical Research Communications, 490(2), 239-246. http://dx.doi.org/10.1016/j. bbrc.2017.06.028. PMid:28606476.

Haas, M. J., Jafri, M., Wehmeier, K. R., Onstead-Haas, L. M., \& Mooradian, A. D. (2016). Inhibition of endoplasmic reticulum stress and oxidative stress by vitamin D in endothelial cells. Free Radical Biology \& Medicine, 99, 1-10. http://dx.doi.org/10.1016/j. freeradbiomed.2016.07.020. PMid:27458123.

Hassan-Smith, Z. K., Jenkinson, C., Smith, D. J., Hernandez, I., Morgan, S. A., Crabtree, N. J., Gittoes, N. J., Keevil, B. G., Stewart, P. M., \& Hewison, M. (2017). 25-hydroxyvitamin D3 and 1,25-dihydroxyvitamin D3 exert distinct effects on human skeletal muscle function and gene expression. PLoS One, 12(2), e0170665. http://dx.doi.org/10.1371/ journal.pone.0170665. PMid:28199350.

Hu, X., Hu, C., Liu, J., Wu, Z., Duan, T., \& Cao, Z. (2021). 1,25-(OH)2D3 protects pancreatic beta cells against $\mathrm{H} 2 \mathrm{O} 2$-induced apoptosis through inhibiting the PERK-ATF4-CHOP pathway. Acta Biochimica et Biophysica Sinica, 53(1), 46-53. PMid:33242093.

Irazoqui, A. P., Boland, R. L., \& Buitrago, C. G. (2014). Actions of 1,25(OH)2-vitamin D3 on the cellular cycle depend on VDR and p38 MAPK in skeletal muscle cells. Journal of Molecular Endocrinology, 53(3), 331-343. http://dx.doi.org/10.1530/JME-140102. PMid:25316911.

Ishimoto, E. Y., Vicente, S. J. V., Cruz, R. J., \& Torres, E. A. F. S. (2020). Hypolipidemic and antioxidant effects of grape processing by-products in high-fat/cholesterol diet-induced hyperlipidemic hamsters. Food Science and Technology, 40(Suppl. 4), 558-567.

Kelley, D. E., Goodpaster, B. H., \& Storlien, L. (2002). Muscle triglyceride and insulin resistance. Annual Review of Nutrition, 22, 325-346. http:// dx.doi.org/10.1146/annurev.nutr.22.010402.102912. PMid:12055349.

Kim, D. H., Klemp, A., Salazar, G., Hwang, H. S., Yeh, M., Panton, L. B., \& Kim, J. S. (2020). High-dose vitamin D administration and resistance exercise training attenuate the progression of obesity and improve skeletal muscle function in obese p62-deficient mice. Nutrition Research, 84, 14-24. http://dx.doi.org/10.1016/j. nutres.2020.10.002. PMid:33199033.

Kwak, H. J., Choi, H. E., \& Cheon, H. G. (2017). 5-LO inhibition ameliorates palmitic acid-induced ER stress, oxidative stress and insulin resistance via AMPK activation in murine myotubes. Scientific Reports, 7(1), 5025. http://dx.doi.org/10.1038/s41598-017-05346-5. PMid:28694473.

Liong, S., \& Lappas, M. (2016). Endoplasmic reticulum stress regulates inflammation and insulin resistance in skeletal muscle from pregnant women. Molecular and Cellular Endocrinology, 425, 11-25. http:// dx.doi.org/10.1016/j.mce.2016.02.016. PMid:26902174.

Montenegro, K. R., Carlessi, R., Cruzat, V., \& Newsholme, P. (2019). Effects of vitamin $\mathrm{D}$ on primary human skeletal muscle cell proliferation, differentiation, protein synthesis and bioenergetics. The Journal of Steroid Biochemistry and Molecular Biology, 193, 105423. http:// dx.doi.org/10.1016/j.jsbmb.2019.105423. PMid:31279004.

Pojednic, R. M., Ceglia, L., Olsson, K., Gustafsson, T., Lichtenstein, A. H., Dawson-Hughes, B., \& Fielding, R. A. (2015). Effects of 1,25-dihydroxyvitamin D3 and vitamin D3 on the expression of the vitamin d receptor in human skeletal muscle cells. Calcified Tissue International, 96(3), 256-263. http://dx.doi.org/10.1007/ s00223-014-9932-x. PMid:25479835.

Reddy, S. S., Shruthi, K., Prabhakar, Y. K., Sailaja, G., \& Reddy, G. B. (2018). Implication of altered ubiquitin-proteasome system and ER stress in the muscle atrophy of diabetic rats. Archives of Biochemistry and Biophysics, 639, 16-25. http://dx.doi.org/10.1016/j. abb.2017.12.015. PMid:29277369.

Ron, D. (2002). Translational control in the endoplasmic reticulum stress response. The Journal of Clinical Investigation, 110(10), 1383-1388. http://dx.doi.org/10.1172/JCI0216784. PMid:12438433.

Salvadó, L., Coll, T., Gómez-Foix, A. M., Salmerón, E., Barroso, E., Palomer, X., \& Vázquez-Carrera, M. (2013). Oleate prevents saturatedfatty-acid-induced ER stress, inflammation and insulin resistance in skeletal muscle cells through an AMPK-dependent mechanism. Diabetologia, 56(6), 1372-1382. http://dx.doi.org/10.1007/s00125013-2867-3. PMid:23460021.

Sun, J. L., Park, J., Lee, T., Jeong, J. H., \& Jung, T. W. (2020). DEL-1 ameliorates high-fat diet-induced insulin resistance in mouse skeletal muscle through SIRT1/SERCA2-mediated ER stress suppression. Biochemical Pharmacology, 171, 113730. http://dx.doi.org/10.1016/j. bcp.2019.113730. PMid:31778646.

Visser, M., Deeg, D. J., \& Lips, P. (2003). Low vitamin D and high parathyroid hormone levels as determinants of loss of muscle 
strength and muscle mass (sarcopenia): the Longitudinal Aging Study Amsterdam. The Journal of Clinical Endocrinology and Metabolism, 88(12), 5766-5772. http://dx.doi.org/10.1210/jc.2003030604. PMid:14671166.

Wen, G., Eder, K., \& Ringseis, R. (2020). 1,25-hydroxyvitamin D3 decreases endoplasmic reticulum stress-induced inflammatory response in mammary epithelial cells. PLoS One, 15(2), e0228945. http://dx.doi.org/10.1371/journal.pone.0228945. PMid:32040528.

Yuan, Y. F., Das, S. K., \& Li, M. Q. (2018). Vitamin D ameliorates impaired wound healing in streptozotocin-induced diabetic mice by suppressing endoplasmic reticulum stress. Journal of Diabetes Research, 2018, 1757925. http://dx.doi.org/10.1155/2018/1757925. PMid:29707582. 